\title{
Comparison of the efficacy of early versus late viral proteins in vaccination against SIV
}

\author{
Koert J. Stittelaar ${ }^{\mathrm{a}}$, Rob A. Gruters ${ }^{\mathrm{a}, \mathrm{b}}$, Martin Schutten ${ }^{\mathrm{a}}$, Carel A. van Baalen ${ }^{\mathrm{a}}$, \\ Geert van Amerongen ${ }^{a}$, Martin Cranage ${ }^{\mathrm{c}}$, Peter Liljeström ${ }^{\mathrm{d}}$, Gerd Sutter ${ }^{\mathrm{e}}$, \\ Albert D.M.E. Osterhaus ${ }^{\text {a,* }}$ \\ ${ }^{a}$ Department of Virology, Erasmus Medical Centre Rotterdam, Dr Molewaterplein 50, 3015 GE Rotterdam, The Netherlands \\ b UMR2142, CNRS/BioMérieux, ENS Lyon, 69364 Lyon Cedex 07, France \\ ${ }^{\mathrm{c}}$ CAMR, Porton Down, Salisbury, Wilts, UK \\ ${ }^{\mathrm{d}}$ Microbiology and Tumorbiology Center, Karolinska Institute, Stockholm, Sweden \\ ${ }^{\mathrm{e}}$ GSF-Institute of Molecular Virology, 85764 Neuherberg, Germany
}

Accepted 17 April 2002

\begin{abstract}
The immune response against early regulatory proteins of simian- and human immunodeficiency virus (SIV, HIV) has been associated with a milder course of infection. Here, we directly compared vaccination with Tat/Rev versus Pol/Gag. Challenge infection with SIVmac32H (pJ5) suggested that vaccination with Tat/Rev induced cellular immune responses that enabled cynomolgus macaques to more efficiently control SIV replication than the vaccine-induced immune responses against Pol/Gag. Vaccination with Tat/Rev resulted in reduced plasma SIV loads compared with control $(P=0.058)$ or Pol/Gag-vaccinated $(P=0.089)$ animals, with undetectable plasma viral loads in two of the four Tat/Rev-vaccinated animals. Therefore, the results warrant further investigation of the early regulatory proteins and their potential for vaccination against HIV.
\end{abstract}

(C) 2002 Published by Elsevier Science Ltd.

Keywords: Tat; Rev; CTL

\section{Introduction}

Candidate lentivirus vaccines have been tested with variable degrees of success but correlates of protective immunity remain largely elusive. Most of the efforts have focussed on the induction of both humoral and cellular responses against structural proteins [1]. However, lentivirus infection generally results in chronic infection and progression to disease despite the presence of these immune responses [2,3].

We have previously found that longterm asymptomatic HIV seropositive individuals have cytotoxic T lymphocyte (CTL) responses against all the HIV proteins tested, whereas rapid progressors initially have comparable CTL responses against structural proteins, but not or very limitedly against Tat and Rev [4]. The possibility that CTL responses against early regulatory proteins are more effective in controlling lentivirus infection was recently also supported by studies on SIV infection in macaques [5-7].

\footnotetext{
* Corresponding author: Postal address: Institute of Virology, Erasmus MC Rotterdam, P.O. Box 1738, 3000 DR Rotterdam, The Netherlands. Tel.: +33-10-4088066; fax: +33-10-104089485.

E-mail address: osterhaus@viro.fgg.eur.nl (A.D.M.E. Osterhaus).
}

Preliminary vaccination experiments in macaques with Tat alone or Tat in combination with Rev yielded encouraging results showing reduced primary SIV viraemia after challenge $[5,8,9]$. In other studies, however, vaccination with structural proteins in some cases also led to reduction of primary viraemia [10]. Comparing efficacy of the different vaccine formulations and schedules is difficult, since different primate models for lentivirus infection vary markedly in their read-out parameters [11]. Therefore, we directly compared the ability of vaccine-induced immunity against the early regulatory proteins Tat and Rev with that against the late structural proteins Pol and Gag to control SIV replication after challenge.

\section{Materials and methods}

\subsection{Immunization and challenge of macaques}

Twelve cynomolgus macaques (Macaca fascicularis) were vaccinated four times intramuscularly in a prime-boost regimen in which two vaccinations with recombinant 
Semliki Forest virus (rSFV; at weeks 0 and 6) were followed by two vaccinations with recombinant modified vaccinia virus Ankara (rMVA; at weeks 12 and 16) expressing Tat and $\operatorname{Rev}(n=4)$, Pol and Gag $(n=4)$ or $\beta$-gal $(n=4)$ [8].

EDTA-blood samples were collected every 2 weeks for plasma and isolation of peripheral blood mononuclear cells (PBMC). Five weeks after the last immunization all macaques were challenged intravenously with $50 \mathrm{MID}_{50}$ SIVmac32H (pJ5).

\subsection{Biochemical analysis of vaccines}

The genes of the respective SIV proteins are all expressed under specific control of the same promotor and similar levels of Rev and Gag expression have been observed in vitro (Fig. 1). CEF cells grown in 6-well tissue culture plates were infected at an MOI of 10 with MVA or rMVA. After $24 \mathrm{~h}$ infected monolayers were harvested by cell lysis. Lysates corresponding to about $5 \times 10^{5}$ infected CEF were separated by SDS-polyacrylamide gel electrophoresis (PAGE). Proteins were electroblotted onto nitrocellulose membranes for $2 \mathrm{~h}$ in a buffer containing $25 \mathrm{mM}$ Tris, $192 \mathrm{mM}$ glycine and $20 \%$ methanol ( $\mathrm{pH}$ 8.6). After blocking overnight in PBS-2\% BSA, blots were probed with 1000-fold dilutions of mouse monoclonal antibodies directed against SIV Rev (MAB 6.2, kindly provided by Kai Krohn, University of Tampere, Finland) or Gag-p27 proteins (KK60, kindly provided by Karen Kent, NIBSC, Potters Bar, UK) in PBS-2\% BSA for $1 \mathrm{~h}$. After being washed with PBS- $0.1 \%$ Nonidet P-40, the blot was incubated for $1 \mathrm{~h}$ with alkaline phosphatase-conjugated polyclonal goat antimouse antibody (Promega, Madison, WI) diluted 2000-fold in PBS-2\% BSA, washed again, and developed using Western blue substrate (Promega, Madison, WI).

\subsection{Serological assays}

MVA-specific plasma IgG was determined using a FACS-measured immunofluorescence assay as described previously with an additional pre-incubation of plasma's on uninfected RK-13 cells [12]. SFV-specific plasma IgG responses were similarly determined using HeLa cells that were used $18 \mathrm{~h}$ after infection with SFV.
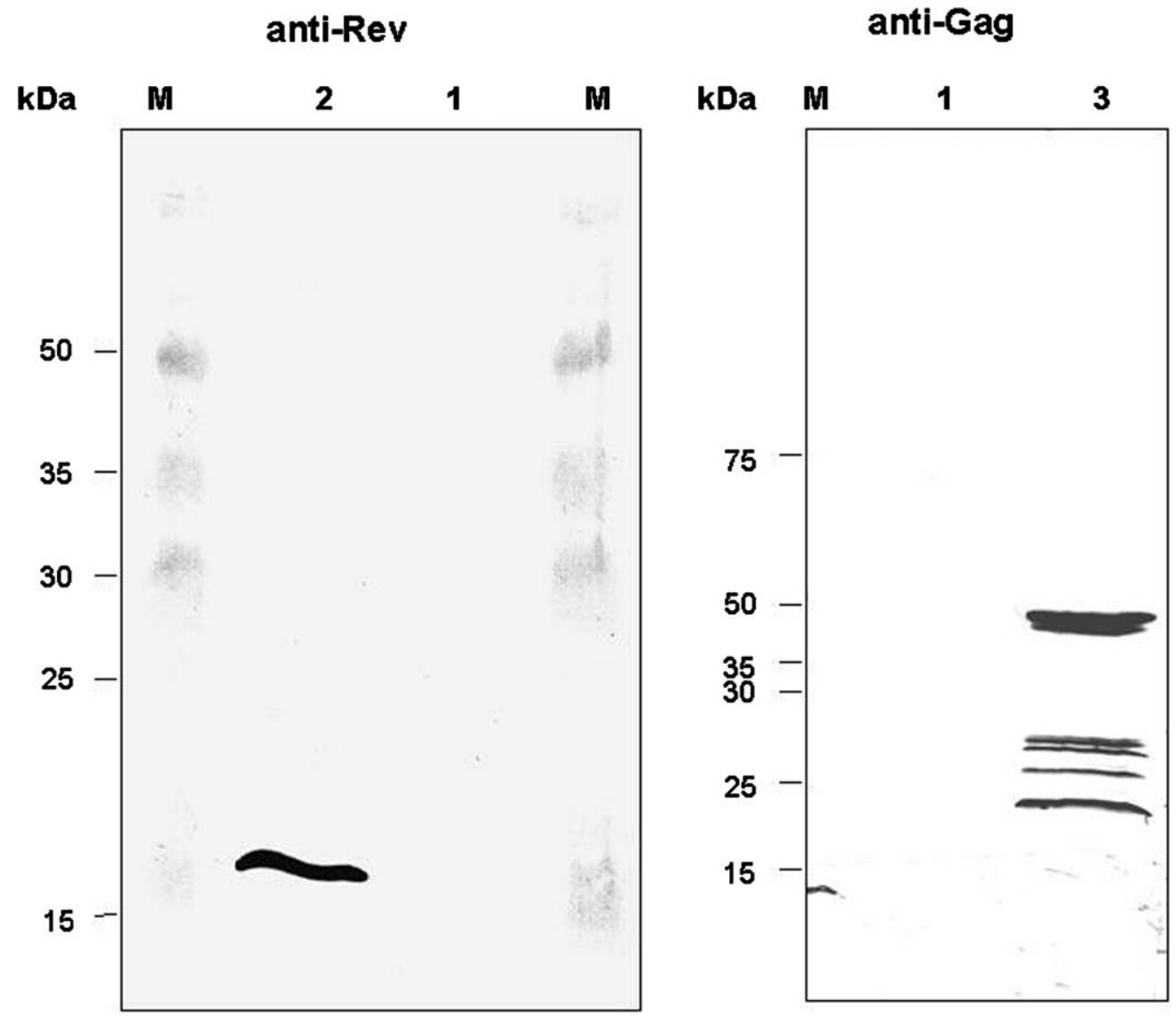

Fig. 1. Western blot analysis of SIV Rev and Gag proteins. Proteins in lysates of CEF infected with wildtype MVA (lane 1) or rMVA expressing the SIVmac protein Rev (lane 2) or Gag-Pol (lane 3) were resolved by SDS-PAGE, transferred to a nitrocellulose membrane, and probed with mouse monoclonal antibodies against SIV Rev (anti-Rev) or Gag (anti-Gag) proteins. M, lanes with protein standards; molecular masses (in kDa) are indicated by the numbers on the left. 


\subsection{Elispot assay}

The frequency of SIV protein-specific interferon-gamma producing cells (IPC) was determined by Elispot for interferon-gamma (IFN $\gamma$ ). PBMC depleted for CD4 cells ( $\triangle$ CD4-PBMC) using CD4 Dynabeads (Dynal, Hamburg, Germany) were cultured overnight in 96-well round-bottomed plates (Greiner, Labor Technik, Nürtingen, Germany) in RPMI-1640 supplemented with penicillin $(100 \mathrm{U} / \mathrm{ml})$, streptomycin $(100 \mu \mathrm{g} / \mathrm{ml})$, L-glutamine $(2 \mathrm{mM}), 2$-mercaptoethanol $\left(10^{-5} \mathrm{M}\right), 10 \%$ FBS and $1 \%$ pooled serum from naïve macaques (referred to as culture medium). After $18 \mathrm{~h}$ cells were counted and seeded in 96-well V-bottomed plates (Greiner) at a concentration of $1 \times 10^{5}$ cells per well (pre-challenge) or $0.5 \times 10^{5}$ cells per well (post-challenge). Autologous herpes papio virus-transformed B cells (B-LCL) were pulsed at a cell density of $1 \times 10^{6}$ cells $/ \mathrm{ml}$ with $10 \mu \mathrm{g} / \mathrm{ml}$ of 20 -mer peptides with 10 amino acids overlapping during $1 \mathrm{~h}$ at $37^{\circ} \mathrm{C}$ in a round-bottomed 96-well plate. Tat-derived peptides (ARP7057.1-12), Rev-derived peptides (ARP7058.1-10) and a selected set of Gag-derived peptides were obtained from Centralized Facility for AIDS Reagents, NIBSC. Gag-derived peptides were selected to contain previously defined CTL epitopes (p26 (ARP714.4-6) p17 (EVA775.2, 5, 11-14, 17 and 21) p15 (EVA776.1-2) (Los Alamos National Laboratory, HIV sequence database). After the pulse, half of the culture medium was replaced by fresh medium without peptide. After overnight incubation at $37^{\circ} \mathrm{C}$ cells were irradiated (30 Gy) and added to the $\triangle \mathrm{CD} 4-\mathrm{PBMC}$ at a 1:2 ratio. Plates were centrifuged briefly, incubated at $37^{\circ} \mathrm{C}$ for $1 \mathrm{~h}$ and cells were transferred to Elispot plates coated with mouse monoclonal IFN $\gamma$-specific antibody (U-CyTech, Utrecht, The Netherlands). Six hours later, cells were transfered to a round-bottomed 96-well plate and maintained in culture medium supplemented with recombinant IL-2 during about 10 days. Subsequently, cells were expanded using PHA and xenogenic stimulation for future analysis of specific CTL epitopes. Elispot plates were developed with biotinylated rabbit polyclonal IFN $\gamma$-detecting antibody (U-CyTech) followed by streptavidin alkaline phophatase conjugate (DAKO, Glostrup, Denmark) and BCIP/NBT phosphatase substrate (Kirkegaard \& Perry Laboratories, Gaithersburg, USA). Developed spots were quantified by light microscopy.

\subsection{Virus detection}

SIV plasma viraemia was monitored by real-time RT-PCR. We quantified viral RNA using a Taqman assay (forward primer, 5'-CTTGGTCCATGGGGAAAGAA-3'; reverse primer, 5'-TCAGCCCCTGATGCACTTG-3' and FAM/TAMRA-labelled probe, 5'-CCCCGCAATTTCCCCATGGC-3') [13]. Serial dilutions of $\operatorname{SIV}_{\text {mac251 viral }}$ lysate (SanverTECH, Heerhugowaard, The Netherlands) were spiked into negative plasma and used to calculate the RNA copies $/ \mathrm{ml}$. The cell-associated viral load was determined with an infectious center test on c8166 cells [14].

\subsection{Statistical analysis}

We used repeated measures analysis of variance (rmANOVA), assuming a compound symmetry structure for the residual (co)variance matrix. For testing the mean difference in plasma load of viral RNA between groups, we used $\ln$-transformed data from day 3 to 109 . Values below the detection limit of the real-time quantitative RT-PCR assay were set to 500 copies $/ \mathrm{ml}$.

\section{Results}

\subsection{Antibody response against the vectors}

Animals were vaccinated in a prime-boost regimen, with two doses of rSFV followed by two doses of rMVA, for optimal induction of cellular immunity [15]. Vaccinations were monitored via vector-specific antibodies in the plasma. After each administration, antibody titers increased, reaching similar levels in all groups at the end of the vaccinations (Fig. 2). The kinetics of SFV- and MVA-specific antibody responses were largely similar in all macaques upon primary and secondary vaccination, showing that indeed all the macaques were vaccinated and that re-vaccination boosted the immune response against the respective vectors (Fig. 2). SIV antigens did not seem to interfere with the induction of the immune response, despite reported immuno-modulatory effects for Tat [16].

\subsection{Cellular immune response against SIV proteins}

The number of SIV-specific IPC was quantified with an Elispot. At the day of challenge, no SIV-specific IPC were found in the control animals (Fig. 3). In Tat/Rev-vaccinated animals IPC against Tat and Rev (40-6880 IPC/ $10^{6}$ $\triangle \mathrm{CD} 4-\mathrm{PBMC}$ ) could be demonstrated, but not against Gag. Conversely, Gag/Pol-vaccinated animals had developed IPC against Gag (10-2700 IPC/10 $\triangle 0^{6}$ CD4-PBMC), but not against Tat or Rev.

After challenge, when viral loads declined, control animals had developed a cellular immune response against SIV. This was demonstrated by moderate levels of IPC against all three antigens tested (Fig. 3; 60-1220 IPC $/ 10^{6} \Delta$ CD4-PBMC). In Tat/Rev-vaccinated animals, IPC against vaccine antigens were still detectable, but only one animal had developed low numbers of IPC against Gag. Similarly, Gag-specific responses were retained in animals vaccinated with Gag/Pol and two animals had acquired low numbers of IPC specific for Tat and Rev. 

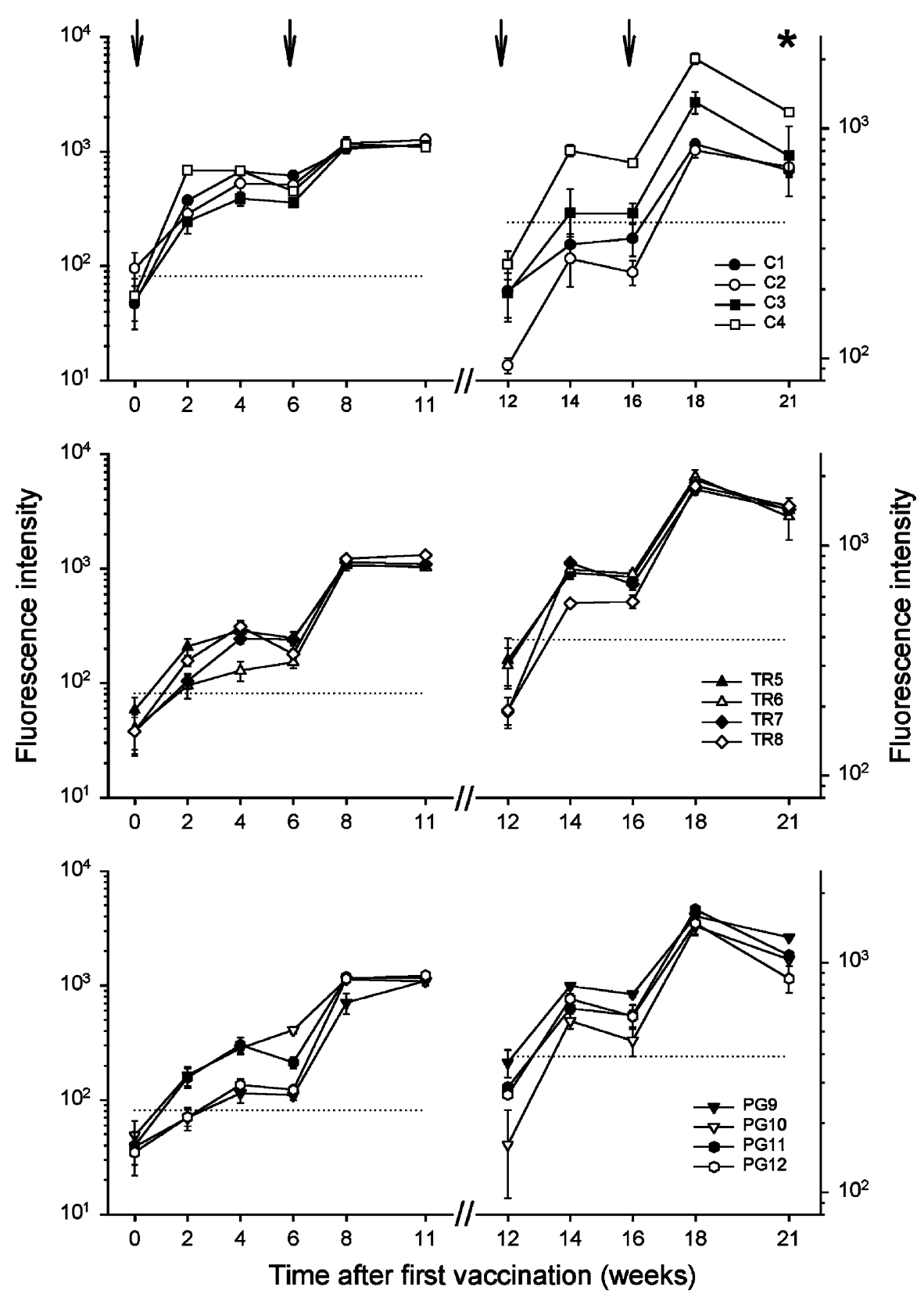

Fig. 2. Development of IgG plasma responses against the vaccine vectors (rSFV; left and rMVA; right) in macaques vaccinated with control vectors (top), Tat and Rev expressing vectors (middle) and Pol and Gag expressing vectors (bottom). The four vaccinations are indicated (arrows) as well as the moment of infection SIV infection (asterisk). The data are presented as fluorescence intensity (average \pm S.D.). An arbitrary cut-off level was chosen at the average $+2 \times$ S.D. (dotted line).

\subsection{SIV viral loads}

After challenge with the high dose of infectious virus all animals became infected (Table 1). One control animal became persistently viremic and three had a transient viraemia which is common for this model of lentivirus infection [17]. Two of the Tat/Rev-vaccinated animals remained negative for plasma viraemia (Fig. 4). The other two had a short viraemia, with little virus production. By contrast, Gag/Pol-vaccinated animals all developed detectable plasma viral loads similar to the control animals and two were still positive at the end of the observation period. The differences between the groups were only borderline significant (Tat/Rev versus control $P=0.058$ and Tat/Rev versus Pol/Gag $P=$ $0.089)$, likely due to the small number of animals tested.

The data from the infectious centre test showed similar trends as the plasma viral loads. From all animals, virus could be isolated at some stage after challenge (Table 1). The Tat/Rev-vaccinated animals cleared the virus infected cells faster and only one animal had remained virus 


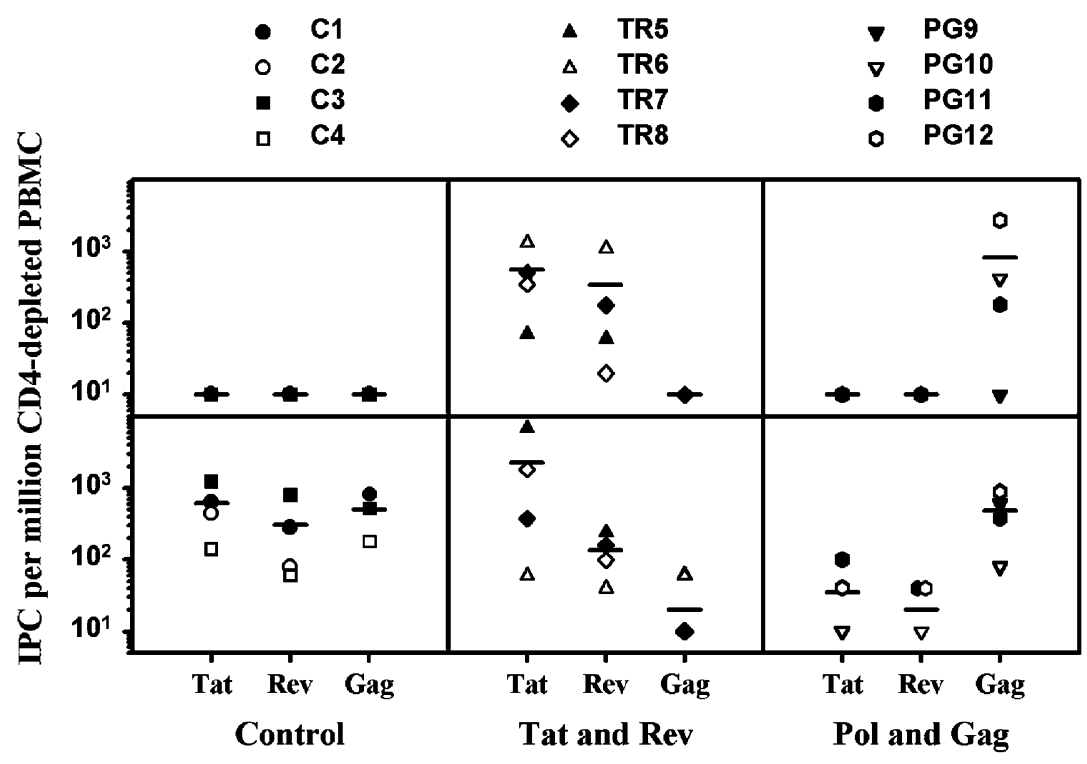

Fig. 3. Numbers of Tat-, Rev- and Gag-specific IFN $\gamma$-producing cells (IPC) in CD4-depleted PBMC collected at the day of challenge (upper panel) or at day $20^{*}$ after challenge (lower panel) assessed by an Elispot assay. Spots were quantified visually by light microscopy. ${ }^{*}$ Occasionally, when PBMC collected at day 20 were not available, samples from day 27 or 33 were used instead (\#TR6 and \#TR8: Gag peptides, \#PG12: Tat and Rev peptides). The horizontal lines in the graphs indicate the mean value of the group.

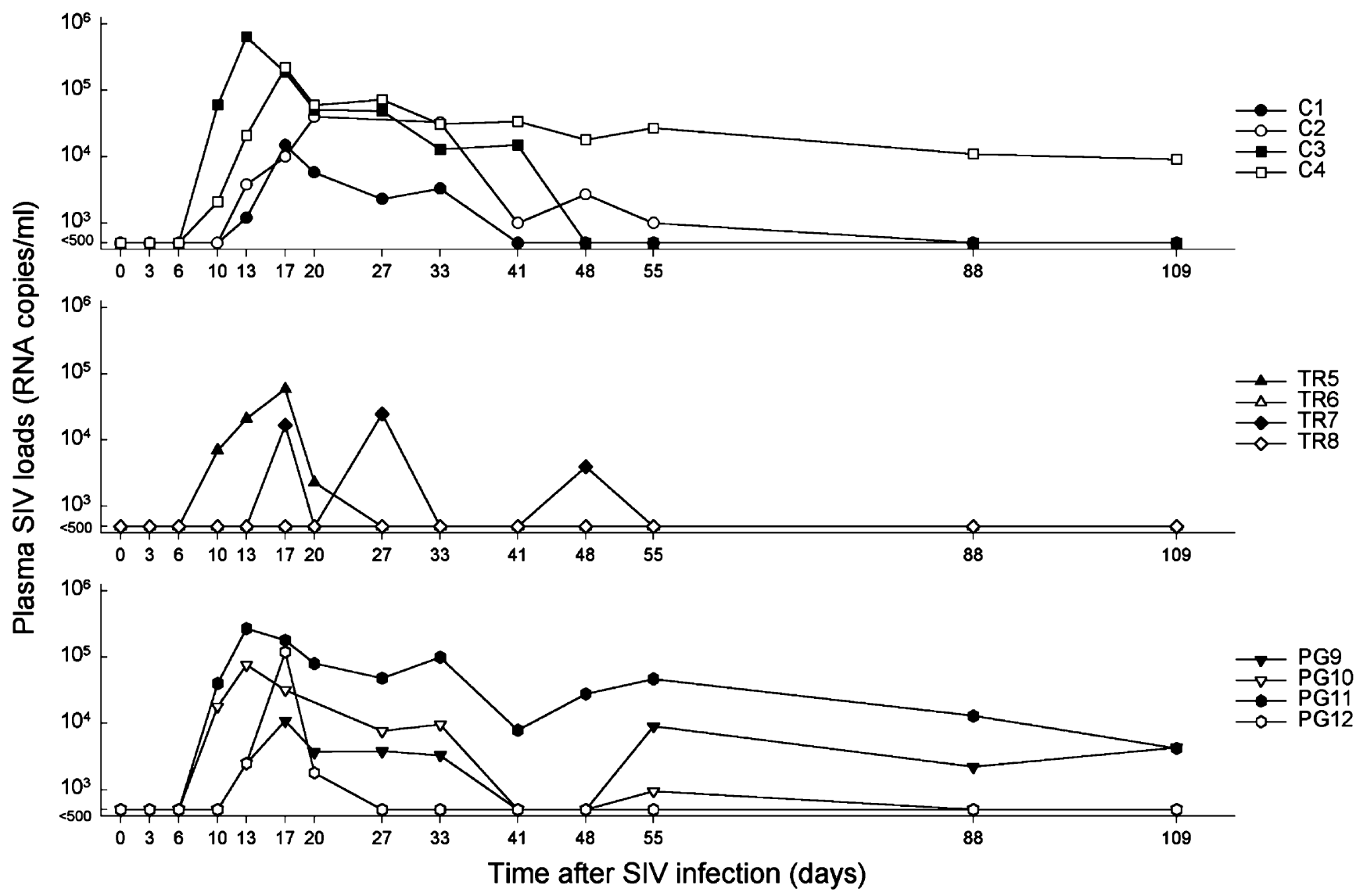

Fig. 4. Detection of plasma viral loads. Plasma viraemia was measured using a real-time quantitative RT-PCR [13]. The detection cut-off was 500 SIV RNA copies/ml. 
Table 1

Detection of cell-associated viral load

\begin{tabular}{|c|c|c|c|c|c|c|c|c|c|c|c|c|}
\hline \multirow[t]{2}{*}{ Day after SIV challenge } & \multicolumn{4}{|c|}{ Control } & \multicolumn{4}{|c|}{ Tat and Rev } & \multicolumn{4}{|c|}{ Pol and Gag } \\
\hline & $\mathrm{C} 1$ & $\mathrm{C} 2$ & $\mathrm{C} 3$ & $\mathrm{C} 4$ & TR5 & TR6 & TR7 & TR8 & PG9 & PG10 & PG11 & PG12 \\
\hline 3 & $-^{\mathrm{a}}$ & - & 1 & 1 & 1 & 1 & 1 & - & 25 & 1 & - & - \\
\hline 6 & - & - & 125 & 1 & - & - & - & - & 5 & - & - & - \\
\hline 10 & 1 & 25 & $\geq 625$ & 125 & 125 & 25 & 1 & 1 & 125 & 125 & $\geq 625$ & 125 \\
\hline 13 & 25 & 125 & $\geq 625$ & $\geq 625$ & $\geq 625$ & $\geq 625$ & 5 & 25 & 125 & $\geq 625$ & $\geq 625$ & $\geq 625$ \\
\hline 17 & 25 & $\geq 625$ & $\geq 625$ & $\geq 625$ & 125 & 5 & $\geq 626$ & - & $\geq 625$ & $\geq 625$ & $\geq 625$ & $\geq 625$ \\
\hline 20 & $\geq 625$ & $\geq 625$ & 125 & $\geq 625$ & $\geq 625$ & 125 & $\geq 625$ & 1 & $\geq 625$ & $\geq 625$ & $\geq 625$ & $\geq 625$ \\
\hline 27 & $\geq 625$ & $\geq 625$ & 125 & $\geq 625$ & $\geq 625$ & 125 & 25 & 5 & 125 & $\geq 625$ & $\geq 625$ & 25 \\
\hline 33 & 1 & 125 & 125 & 25 & 25 & 1 & 125 & - & 25 & 5 & 25 & - \\
\hline 41 & 1 & 25 & 25 & $\geq 625$ & 25 & - & 5 & - & 25 & 25 & 25 & - \\
\hline 48 & 1 & 25 & - & $\geq 625$ & 25 & - & 5 & - & 125 & 25 & $\geq 625$ & - \\
\hline 55 & - & 5 & 5 & $\geq 625$ & - & - & 25 & - & 125 & 5 & 125 & - \\
\hline 72 & 125 & - & 25 & 3125 & - & 1 & 5 & - & 25 & 1 & 3125 & - \\
\hline 88 & 5 & - & 25 & 3125 & - & - & 5 & - & 25 & 1 & 3125 & 1 \\
\hline
\end{tabular}

The number of SIV-infected cells per $10^{6}$ PBMC isolated from blood samples collected at different days after intravenous infection with 50 MID 50 SIVmac32H (pJ5) were detected using an infectious center test [17].

a Less than one infected cell per $10^{6}$ PBMC.

positive at the end of the experiment. By contrast, infected cells were persistently detected in $3 / 4$ and $4 / 4$ control and Gag/Pol-vaccinated animals, respectively.

\section{Discussion}

Here, we compared the effect of vaccination with early versus late SIV proteins on the induction of specific immunity and containment of challenge. The SIV-vaccinated animals, but not the control animals, had developed SIV-specific IPC at the day of challenge. Despite pre-existing immunity, all animals became infected, but two Tat/Revvaccinated animals with high numbers of Tat-specific IPC remained negative for plasma viraemia. There was, however, a provocative trend in that Tat/Rev-vaccinated animals better controlled viraemia.

We and others previously found that, CTL against structural proteins are ubiquitous in lentivirus infection, but that Tat/Rev-specific CTL correlate with a low viraemia and a benign course of infection $[4,17,18]$. From these data it could not be inferred whether the beneficial effect of Tat/Rev-specific CTL was the consequence of a broader response in general, or whether it was intrinsic to Tat and/or Rev-specific CTL. Our current study argues against the breadth of the immune response as an explanation, since each vaccine contained two proteins. Moreover, Gag and Pol are much larger proteins and may, therefore, induce more CTL populations with different specificities. Therefore, we favor the hypothesis that early expression of Tat and Rev during the virus replication cycle contributes to timely elimination of infected cells and more effective reduction of the amount of virus produced (van Baalen, submitted).

Of note, a bias in the immune response of the vaccinated macaques was observed after challenge. Whereas control animals developed IPC against all antigens tested, vaccinated animals had a preference for the antigens used in vaccination. This may have resulted from immune-mediated limitation of viral replication, which could hamper sensitization to SIV antigens that were encountered only after vaccination. This explanation is, however, not consistent with the data. Two of the three animals that developed IPC against non-vaccine antigen showed no (TR6) or limited (PG12) plasma viraemia after challenge. In all animals with high vireamia, an increase in IPC against SIV antigens that were included in the vaccine was observed. On the other hand, the immune system may have become skewed towards the antigens as a result of the vaccination. In that case, and if CTL against early proteins are indeed more protective, vaccination with viral structural proteins may be suboptimal or even counterproductive.

In this study, vaccination with $\mathrm{Gag} / \mathrm{Pol}$ did not result in any noticeable effect on virus replication, whereas in other studies some protection has been reported [10]. It is important to realize these vaccinations have been carried out in different models, which may explain the discrepancy in results. Infection of cynomolgus macaques with SIVmac32H (pJ5) results in low level, transient viraemia, which is milder than HIV-1 in humans. Other primate models for lentivirus infection give much higher viral loads during primary infection and a more rapid progression to disease and death than HIV-1 infection [11]. It will therefore, be useful to perform comparative studies in these models to further evaluate the effectiveness of different vaccine strategies against HIV.

Collectively, our and other observations point to an advantage of specific immunity directed against the early proteins Tat and Rev in controlling viraemia in lentivirus infections $[5,8,9]$. Therefore, we emphasize that the use of early regulatory proteins should be given serious consideration in the development of HIV vaccination strategies [4]. 


\section{Acknowledgements}

We thank R. Dias d'Ullois, H.W. Vos, P. de Jager, P. Boers, E.J. Verschuren, J. Frerichs, S. van Rosmalen, M. Ohlmann and H.H. Timmerman for technical support and Dr. P.G.H. Mulder for statistical analysis. The work was supported by grants to K.J.S. (NIH: 1R21AI45368-01A1), to C.A.v.B. (Dutch AIDS foundation, 4009), and to G.S. (EU, QLK2-2000-1040). The peptides for the Elispot assay were provided by the EU Programme AVA/MRC Centralized Facility for AIDS Reagents, NIBSC, UK (Grant numbers: QLK2-CT-1999-00609 and GP828102).

\section{References}

[1] Nathanson N, Mathieson BJ. Biological considerations in the development of a human immunodeficiency virus vaccine. J Infect Dis 2000;182:579-89.

[2] Paul WE. Can the immune response control HIV infection? Cell $1995 ; 82: 177-82$

[3] McMichael AJ, Rowland-Jones SL. Cellular immune responses to HIV. Nature 2001;410:980-7.

[4] van Baalen CA, Pontesilli O, Huisman RC, Geretti AM, Klein MR, De Wolf F, et al. Human immunodeficiency virus type $1 \mathrm{Rev}$ - and Tat-specific cytotoxic $\mathrm{T}$ lymphocyte frequencies inversely correlate with rapid progression to AIDS. J Gen Virol 1997;78:1913-8.

[5] Pauza CD, Trivedi P, Wallace M, Ruckwardt TJ, Le Buanec $\mathrm{H}, \mathrm{Lu} \mathrm{W}$, et al. Vaccination with tat toxoid attenuates disease in simian/HIV-challenged macaques. Proc Natl Acad Sci USA 2000;97:3515-9.

[6] Allen TM, O'Connor DH, Jing P, Dzuris JL, Mothe BR, Vogel TU, et al. Tat-specific cytotoxic $\mathrm{T}$ lymphocytes select for SIV escape variants during resolution of primary viraemia. Nature 2000;407:386-90.

[7] Walker BD, Goulder PJ. AIDS: escape from the immune system. Nature 2000;407:313-4.
[8] Osterhaus ADME, van Baalen CA, Gruters RA, Schutten M, Siebelink CHJ, Hulskotte EGJ, et al. Vaccination with Rev and Tat against AIDS. Vaccine 1999;17:2713-4.

[9] Cafaro A, Caputo A, Fracasso C, Maggiorella MT, Goletti D, Baroncelli S, et al. Control of SHIV-89.6P-infection of cynomolgus monkeys by HIV-1 Tat protein vaccine. Nat Med 1999;5: 643-50.

[10] Mascola JR, Nabel GJ. Vaccines for the prevention of HIV-1 disease. Curr Opin Immunol 2001;13:489-95.

[11] Hirsch VM, Lifson JD. Simian immunodeficiency virus infection of monkeys as a model system for the study of AIDS pathogenesis, treatment, and prevention. Adv Pharmacol 2000;49:437-77.

[12] Stittelaar KJ, Wyatt LS, de Swart RL, Vos HW, Groen J, van Amerongen G, et al. Protective immunity in macaques vaccinated with a modified vaccinia virus Ankara-based measles virus vaccine in the presence of passively acquired antibodies. J Virol 2000;74:423643.

[13] Schutten M, van den Hoogen B, van der Ende ME, Gruters RA, Osterhaus ADME, Niesters HGM. Development of a real time quantitaive RT-PCR for the detection of HIV-2 RNA plasma. J Virol Methods 2000;88:81-7.

[14] Hulskotte EG, Geretti AM, Siebelink KH, van Amerongen G, Cranage MP, Rud EW, et al. Vaccine-induced virus-neutralizing antibodies and cytotoxic $\mathrm{T}$ cells do not protect macaques from experimental infection with simian immunodeficiency virus SIVmac32H (pJ5). J Virol 1995;69:6289-96.

[15] Barouch DH, Letvin NL. DNA vaccination for HIV-1 and SIV. Intervirology 2000;43:282-7.

[16] Rubartelli A, Poggi A, Sitia R, Zocchi MR. HIV-1 Tat: a polypeptide for all seasons. Immunol Today 2001;19:543-5.

[17] Geretti AM, Hulskotte EG, Dings ME, van Baalen CA, van Amerongen G, Norley SG, et al. Decline of Simian immunodeficiency virus (SIV)-specific cytotoxic T lymphocytes in the peripheral blood of long-term non-progressing macaques infected with SIVmac32H (pJ5). J Infect Dis 1999;180:1133-41.

[18] Addo MM, Altfeld M, Rosenberg ES, Eldridge RL, Philips MN, Habeeb K, et al. The HIV controller study collaboration: the HIV-1 regulatory proteins Tat and Rev are frequently targeted by cytotoxic T lymphocytes derived from HIV-1-infected individuals. Proc Natl Acad Sci USA 2001;98:1781-6. 